\title{
Visibility of River Plume Fronts with an X-Band Radar
}

\author{
Satoshi Takewaka \\ Division of Engineering Mechanics and Energy, University of Tsukuba, Tsukuba 305-8573, Japan \\ Correspondence should be addressed to Satoshi Takewaka; takewaka@kz.tsukuba.ac.jp
}

Received 27 July 2015; Accepted 6 September 2015

Academic Editor: Francesco Serafino

Copyright (C) 2016 Satoshi Takewaka. This is an open access article distributed under the Creative Commons Attribution License, which permits unrestricted use, distribution, and reproduction in any medium, provided the original work is properly cited.

\begin{abstract}
A land-based X-band radar was employed to observe river plume fronts at the mouth of the Tenryu River, Japan. Time-averaged radar images captured fronts extending offshore from the river's mouth as bright streaks. Comparisons between satellite optical images and radar images confirm that streaky features in the radar image represent color river plume fronts. Further corroboration comes from field observations of water temperature, salinity, and turbidity conducted simultaneously with the radar measurements. When a survey ship crossed the front, the measured properties varied discontinuously, suggesting that water from the river and sea converged there and also that a downwards current was present. Variation of visibility of the fronts was assessed and compared with the rate of variation of water level and the wind speed and direction. The radar is able to image fronts when the water level is decreasing during ebb tide and the wind speed is over $3 \mathrm{~m} / \mathrm{s}$ along shore. Surface ripple waves are generated by the local wind, and if they propagate across the front, wave heights increase, causing higher backscatter of the emitted radar beam. This observation gives further evidence on the imaging mechanism of river plume fronts with X-band radars in relation to wind direction.
\end{abstract}

\section{Introduction}

River and sea water meet at a river's mouth when the tide is ebbing and form a river plume front observable as discontinuities in surface color, surface roughness of the sea, water temperature, salinity, turbidity, and other physical properties. Observations of river plume fronts have been conducted to characterize the fluid-dynamical aspects and the biological and chemical processes involved in the interaction between land water and oceanic water. Mixing processes of fresh and salt water at the river mouth affect the sedimentation, mixing of suspended solids, and so forth, and those consequences are important from engineering aspects.

Kilcher and Nash [1] gave a comprehensive review on "tidal plume fronts" (in their terminology) which are formed by ebb discharge from a river's mouth. Visual observations [2], instrumental observations $[1,3,4]$, marine radar observations at grazing angle (e.g., $[1,5,6])$, and radar observations from space (e.g., $[7,8]$ ) are the major means of detecting and following river plume fronts with the main purposes of elucidating the spatial and temporal behavior of the fronts, mixing processes, flow structures of river and sea water, and propagation dynamics.
Garvine and Monk [2] made field observations of vertical distributions of current velocity, water temperature, and salinity at the mouth of the Connecticut River, USA. They identified vigorous flow convergence with a sinking motion and change in water surface color at the front. Luketina and Imberger [3] made field observations with multiple instruments at the face of a channel connecting an estuary and Koombana Bay in Australia and described strong convergence and concentrated circulation at the front. In their field measurements, the locations of the fronts were determined by tracing foam lines on the water surface. Marmorino and Trump [4] report results of measurements of the outflow of the Chesapeake Bay in the US into the Atlantic Ocean. Frontal structures on a larger scale compared to the studies noted above were observed, and the existence of similar flow patterns at the front was confirmed. It is widely accepted that there is a flow convergence and vertical circulation at the front, where river and sea water meet, and this will be corroborated by this study also.

Wolff et al. [6] used an X-band imaging radar mounted on the island of Sylt in Germany to observe coastal waves, morphological changes, tide stream patterns, and other features. They averaged the radar images in time to extract 
static signatures and to discuss the flow patterns of tidal cycles. In their work, the time-averaged radar images have caught frontal structures, which is not pointed out explicitly. Pritchard and Huntley [5] analyzed the formation and evolution of a tidally modulated river plume based on X-band radar observations at the mouth of a small river in the English Channel. An outflow of a semicircular river plume was captured in the radar images, and the rate of radial spreading was estimated from the sequence of images. Kilcher and Nash [1] performed "front-tracking" experiments of currents offshore of the Columbia River, which flows into the Pacific Ocean in the US using acoustic Doppler profiler. Surface backscatter from an X-band radar mounted on a survey ship was used to trace the position, shape, and orientation of the front during the measurements. The authors regarded the bands of higher radar backscatter as regions where surface flow converged.

Satellite radar observations are also capable of detecting river front plumes. Images of synthetic aperture radar (SAR) have been analyzed to understand the behavior of outflows of large rivers. Hessner et al. [7] analyzed the behavior of river plume fronts observed along the Rhine River outflow into the North Sea by European radar satellites ERS-1 and ERS-2. They assert that the formation and the locations of the frontal features are mainly linked to the semidiurnal tidal phase in the outflow region. Jay et al. [8] studied the interaction of Columbia River plumes with the California Current and used radar images captured by RADARSAT-1 to understand their synoptic behavior.

Most of these studies using radar images are predicated on temporal field observations being meaningfully correlated to the behavior of river plume fronts; however, they are snapshots of tidal cycles, and so, for example, the variation in the visibility, or definition, of the fronts in the radar images and its dependence on environmental conditions are not well understood. Alpers [9] discusses the imaging of oceanic internal waves and ocean bathymetry with satellite radars. If an internal wave exists, horizontal flows are induced along the sea surface, resulting in local amplification of surface waves and higher backscatter due to enhanced Bragg scattering of radar beams. Alpers et al. [10] further describe the imaging of underwater topographies from space when surface waves are locally amplified by accelerated or decelerated tidal flows above uneven bottoms. They give optimal wind conditions for observing these features in radar images: (1) wind-generated small-scale surface roughness with a wavelength of a few centimeters for the backscatter of microwaves and (2) optimum wind speeds for detecting these features that are from 3 to $6 \mathrm{~m} / \mathrm{s}$. Dependence of backscatter on the wind, surface current, and surface waves is discussed for a theoretical model of a vertical cross section of the ocean by Romeiser and Alpers [11]. The amount of backscatter is estimated for surface waves propagating upwind and downwind.

The author has employed a land-based X-band radar to observe the behavior of river plume fronts continuously during tidal cycles over many years. The radar is installed on the roof of a building close to the mouth of the Tenryu River, in Japan. The hourly processed radar images show streaky features extending offshore from the river's mouth, similar to river plume fronts. The origin of this feature is examined in the light of satellite images, simultaneous field observations, and radar measurements. The definition of the river plume fronts captured in the radar images was assessed by visual inspection, and its dependence on the variation of the water level and local wind is discussed. Higher definition is frequently observed when the water level is falling and the alongshore component of the local wind speed exceeds $3 \mathrm{~m} / \mathrm{s}$. This observation leads to a discussion of the imaging mechanism of river plume fronts with the radar, especially the dependence on the local wind direction and the extent of the river plume front.

\section{Study Site and the Radar Observations}

The Tenryu River flows to the Enshu Coast (lat/long: N34.6472/E-137.7933), Japan, as shown in Figure 1(a). The coast, facing the Pacific Ocean, suffers from severe erosion, and, consequently, enhancement of sediment supply from the catchment is being planned to mitigate the erosion. The river basin area is $5,090 \mathrm{~km}^{2}$, and the length of the river is $213 \mathrm{~km}$. Observation by a land-based X-band imaging radar, in this context, helps us understand the morphology and hydrodynamics by capturing spatial distributions and temporal variation of water lines of the river channel and coastlines and wave propagation in the shallow area [12].

The radar employed in this study is a conventional commercial marine X-band radar (JMA-3925-9 Japan Radio Co. Ltd., incoherent radar, $3 \mathrm{~cm}$ wavelength, $25 \mathrm{kw}$ transmitting power, HH-polarization, and $0.08 \mu$ s radar pulse length), which is usually installed on fishery or commercial boats. The $2.8 \mathrm{~m}$ antenna rotates with a period of approximately $2.6 \mathrm{~s}$ and transmits with a beam width of $0.8^{\circ}$ in the horizontal plane and $25^{\circ}$ in the vertical plane, respectively. The radar is installed on the roof of a sewage plant located near the mouth of the river, as depicted in the satellite image in Figure 1(b). The measurements started in June of 2007 and are still ongoing as of 2013. All the dates and times are displayed in Japanese Standard Time (JST) in the following.

Backscatter, or echo signals, from the sea surface, socalled sea clutter, are sampled at $20 \mathrm{MHz}$ with a specially designed A/D-board installed on a Windows PC. The signals are then converted to a rectangular image of 1024 pixels in both the Cartesian coordinates. Each pixel corresponds to a square of $5.43 \mathrm{~m}$, which is smaller than the theoretical spatial resolution $7.5 \mathrm{~m}$ of the radar system as determined from the pulse length of the emitted beam [13]. There are two main scattering mechanisms for backscatter from the sea surface [14]. The first is Bragg scattering from gravity-capillary waves when the length of the roughness is half the wavelength of the radar beam, which is $1.5 \mathrm{~cm}$ in this study. The second is backscatter that comes from steep and breaking waves, especially in shallow waters. For a horizontally polarized radar beam, that is, for $\mathrm{HH}$-polarization, the latter is stronger than the Bragg scattering.

Time-averaged radar images over $17 \mathrm{~min}$. are processed hourly, as shown in Figure 1(c), which enables identification of water lines of the river channel, dune locations, shore 


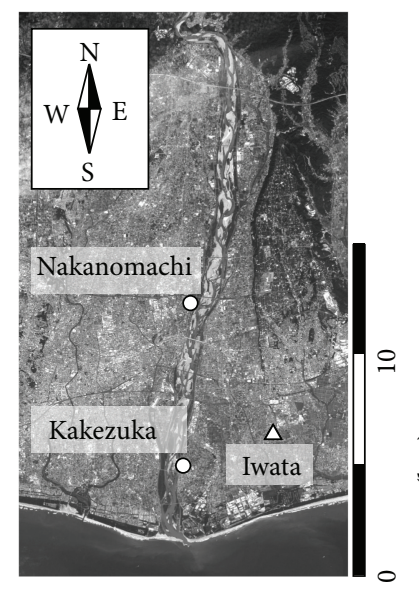

(a)

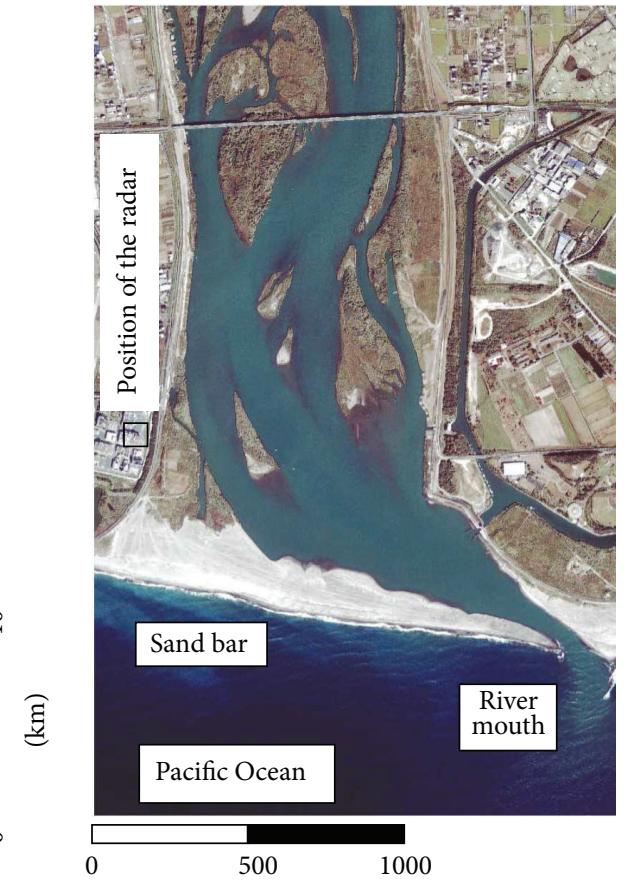

$(\mathrm{m})$

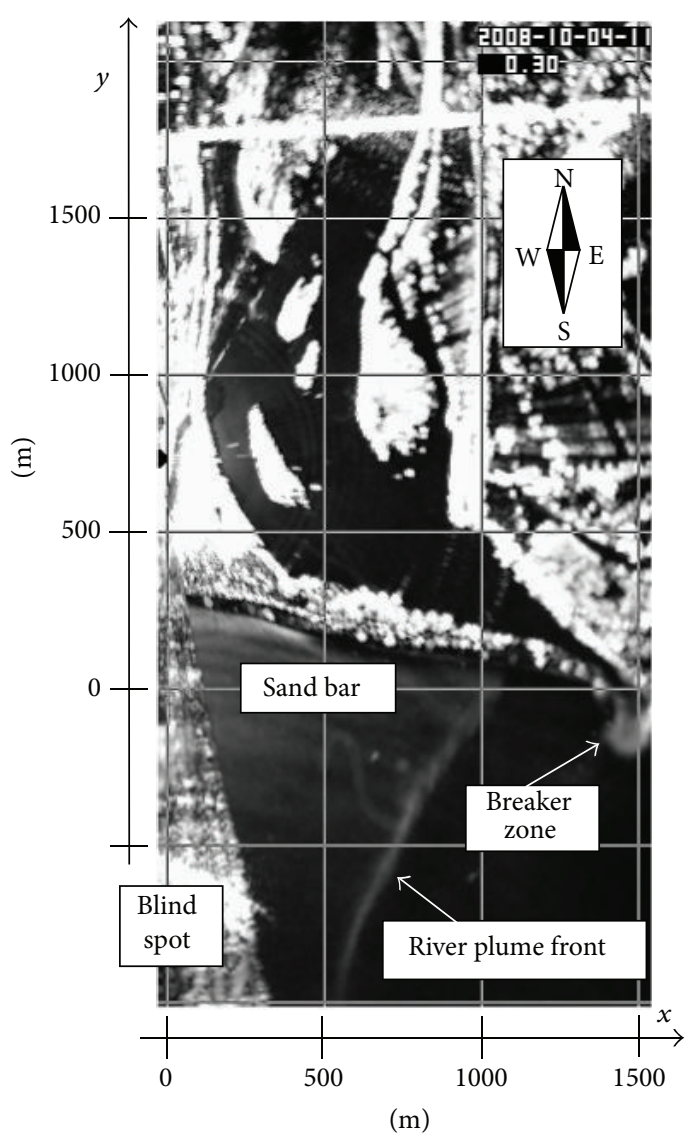

(c)

FIgURE 1: Location of the site: (a) River Tenryu and its fluvial plain, O: gauging station (Nakanomachi, Kakezuka). $\triangle$ : weather station (Iwata). (b) Satellite optical image of the study area, the river's mouth, (Ikonos-2 satellite, acquisition time: 4 October, 2008, 10:54). (c) Time-averaged radar image (average of instantaneous images collected during 11:00 to 11:17 of 4 October, 2008). A river plume front is extending from the sand bar. Breaker zone is formed at the shoal of the river mouth.

positions, breaker zones, and other features. The gray images have pixel intensities between 0 and 255, with brighter pixels corresponding to points with higher signal returns. Comparison with optical satellite data indicates the highest echo signals, depicted with a bright intensity, come from solid surfaces, such as dunes and floodplains, and shallow waters with rough surface due to wave breaking. Smooth sea surfaces return only a small amount of the emitted beam, so they are dark in the time-averaged radar images. A fan-like spot lies on the left side of the averaged radar image, where the radar beam is interfered with by a tower on the sewage plant. The figure also shows the coordinate system used in the studythe $x$-coordinate for east-west extent and the $y$-coordinate for north-south.

In Figure 1(c), a streak denoted as "River front plume" extending offshore from the designated sand bar may represent a front where fresh and salt water encounter. This feature is not always detectable, and the origin of the pattern in the radar image will be discussed in this report. Figure 2 contains an example of a sequence of radar images time-averaged over 8 hours with and without a streaky pattern. The streaky pattern extends offshore from the vicinity of the river's mouth with different inclinations depending on the tidal phase. The bracketed digits encode the definition, or the intensity of the front, as assessed by inspection. Details of these features and the assessment are discussed later on.

\section{Color Fronts Captured in Satellite Images and Streaky Patterns Captured in the Radar Images}

River plume fronts are observed in the field as sharp changes in the sea surface color, or as a color front [2]. The water from the river contains a higher concentration of suspended solids than the sea water. The sea surface also frequently shows an abrupt change from a smooth one to a rough one across the front: vertical circulation is formed at the front and resultant velocity gradient at the surface alters the amplitudes of surface riffles $[3,4]$. Here, satellite images and time-averaged radar images are compared to understand the origin of the streaky pattern.

Figure 3(a) shows a comparison between an optical image acquired by ALOS satellite on July 24, 2008, and 

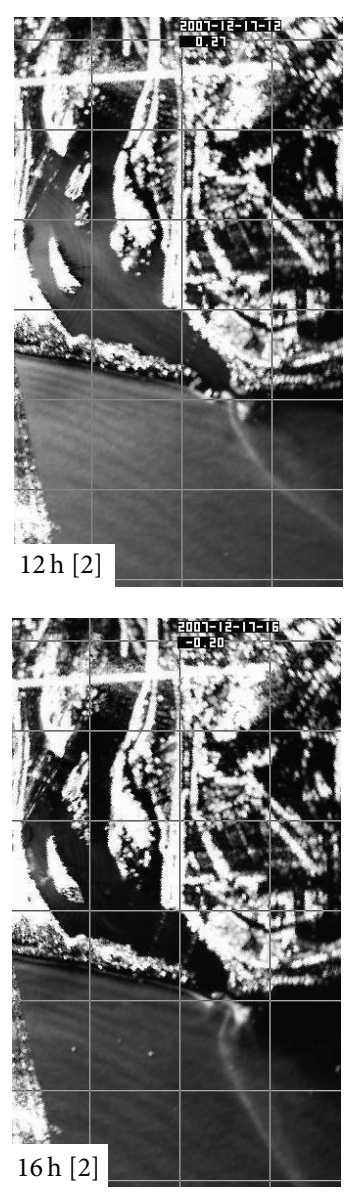
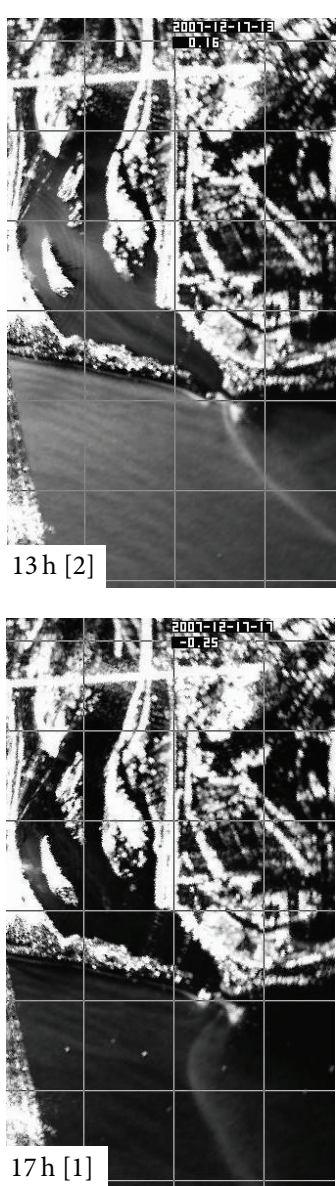
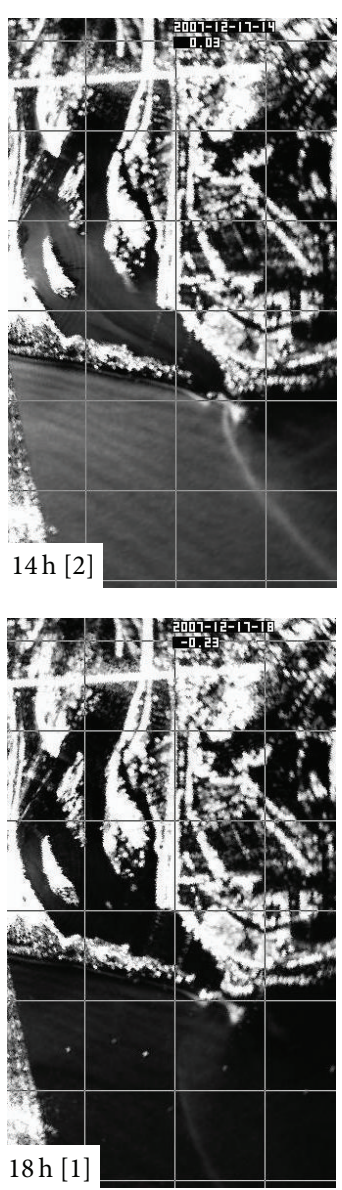
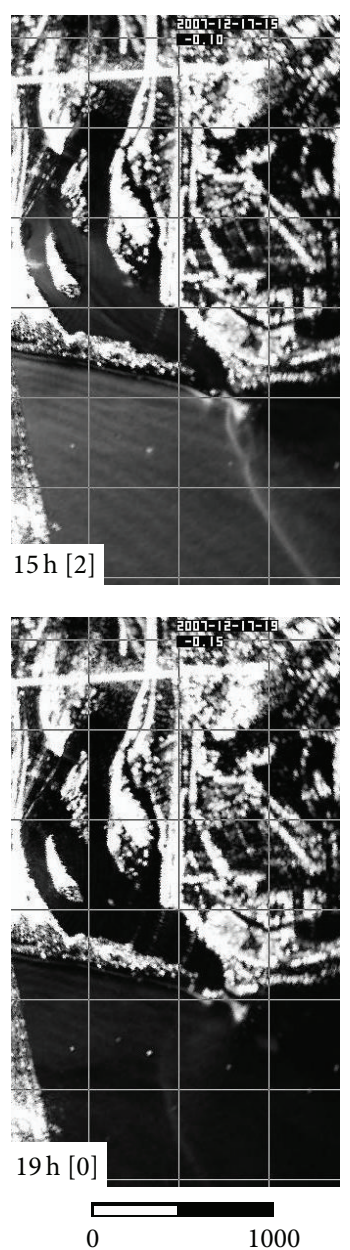

$(\mathrm{m})$

FIGURE 2: Sequence of time-averaged radar images during ebbing period of 17 December, 2007, 12:00-19:00. Each square of the grid corresponds to a square of $500 \mathrm{~m}$. The number in bracket is the definition of the river plume front, or the front intensity, assessed by inspection.

time-averaged radar image. The sea surface close to the river's mouth captured in the satellite image has a complex texture; the color of the sea surface changes abruptly along the streaks, which extend broadly in a net-like manner. Waves approaching the shore during the period of observation had modest heights and are captured as parallel patterns with short wave lengths. A streak in the time-averaged radar image extends offshore from the river's mouth along a path similar to that of one of the streaks observed in the satellite image. Figure 3(b) shows another comparison between an optical image and time-averaged radar images. An outflow of turbid water from the river to the sea is clearly captured in the satellite image, forming a sharp color front extending offshore from the river's mouth. In the time-averaged radar images, a vertical streak extends from the mouth in a manner similar to that in the satellite image. The streak migrates slightly to the west in one hour.

The two comparisons shown here suggest that streaky patterns in the time-averaged radar images correspond to changes of sea surface texture or so-called color fronts formed on the sea in front of the river's mouth.

\section{Field Observations}

In the preceding section, satellite images were used to confirm the origin of the streaky patterns captured in the timeaveraged images. Field observation data will be displayed here for further corroboration.

An in situ towing measurement of water temperature, salinity, and turbidity was conducted across the river plume front on 24 July, 2008, just after a satellite observation was done, simultaneously with the radar observation as summarized in Figure 4. The ship's path is juxtaposed in Figure 4(a) with the streaky feature, or the river plume front, captured in the time-averaged radar image. The ship crossed the front two times, approximately at $12 \mathrm{~h} 12 \mathrm{~m}$ and $12 \mathrm{~h} 24 \mathrm{~m}$. Figure $4(\mathrm{~b})$ is a photo taken from the ship looking towards the river's mouth at the moment when the ship crossed the front approximately at $12 \mathrm{~h} 12 \mathrm{~m}$. A westerly wind with a speed of $1.4 \mathrm{~m} / \mathrm{s}$ for this period was measured at the Iwata weather station, Japan Meteorological Agency, shown in Figure 1(a). The color and roughness of the sea surface suddenly change along a strip extending from the river's mouth. Since the wind field may 
ALOS: 24 July 2008, 10:37 JST

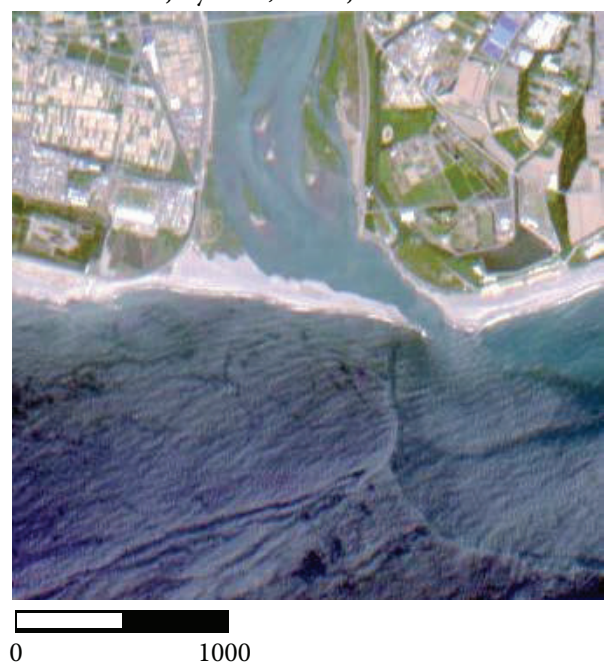

(m)

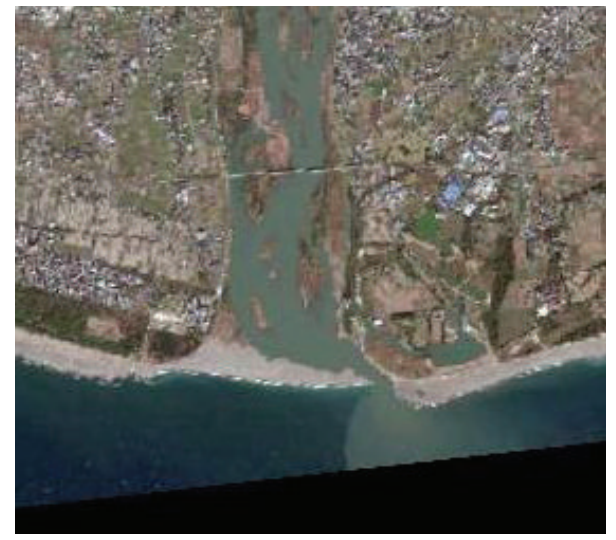

GeoEye-1

21 November 2009, 10:47 JST

(a)
Radar: 11:00-11:17 JST

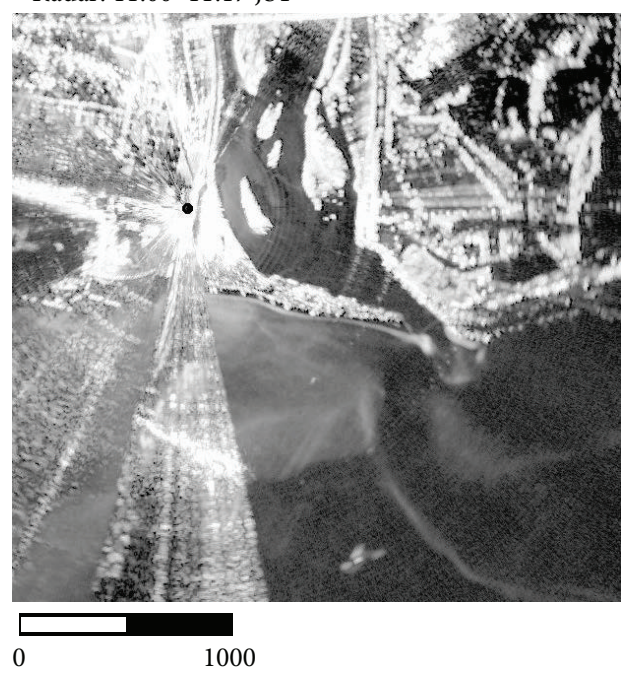

(m)
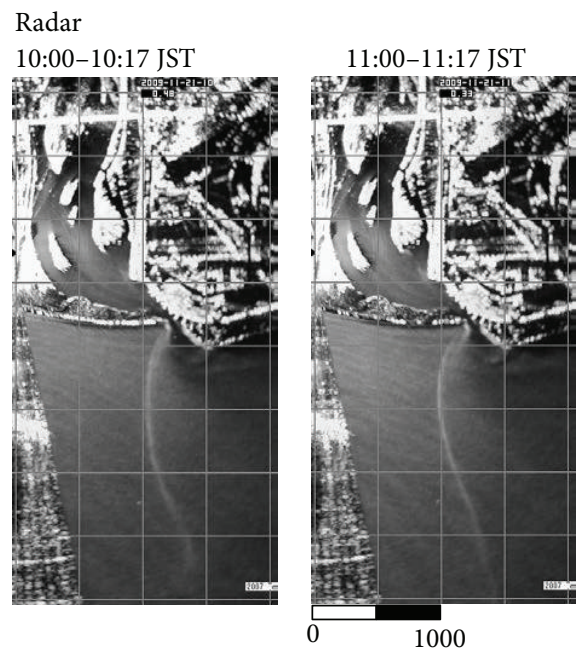

(m)

(b)

FIGURE 3: Comparisons between satellite images and time-averaged radar images. (a) Satellite image: ALOS (24 July, 2008, 10:37) and timeaveraged radar image (24 July, 2008, 11:00-11:17), (b) satellite image: GeoEye (21 November, 2009, 10:47) and time-averaged radar images (21 November, 2009). The ring-shaped features which appear in the time-averaged images of the lower panels are due to some interference in the radar observation; however, its cause is not known.

be regarded as locally uniform in the vicinity of the mouth, the gap in roughness must be due to the internal structure of the flow field beneath the water's surface, which affects the propagation and deformation of the locally generated surface ripple waves.

Figure $4(\mathrm{c})$ presents the time histories of the mean turbidity and salinity records measured with a data logger CTD manufactured by Alec Electronic Instruments. Turbidity is measured from the amount of infrared backscatter and salinity, from conductivity. Data were sampled at a rate of $2 \mathrm{~Hz}$, and the instrument was kept at a depth of 1 to $2 \mathrm{~m}$ from the water's surface. The eastern area of the river plume front, denoted as "plume," is the area that should be under the influence of the river water; the salinity is relatively low and the turbidity is high compared to those measured in the western area of the river plume front, denoted as "ocean." This suggests that the change in water surface color observed from the ship is due to the difference in concentration of suspended solids between the river and the sea water.

Figure 4(d) shows the vertical water temperature distribution measured with a thermistor chain of length approximately $7 \mathrm{~m}$. A thermal stratification was formed by solar 


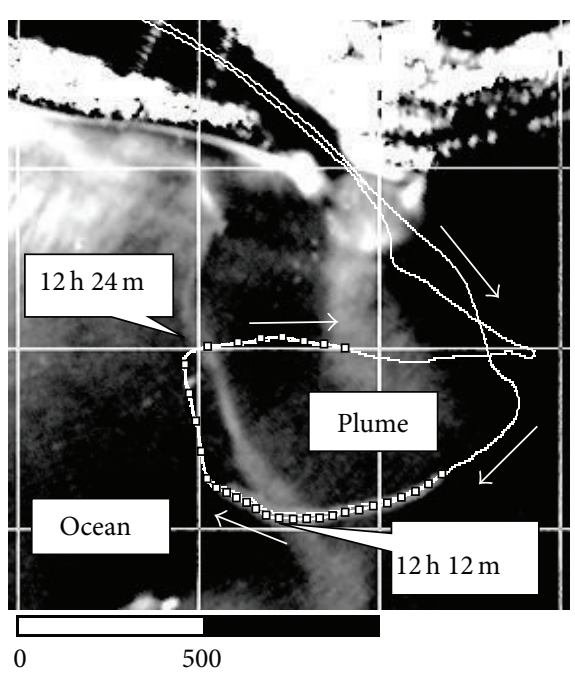

(m) (a)

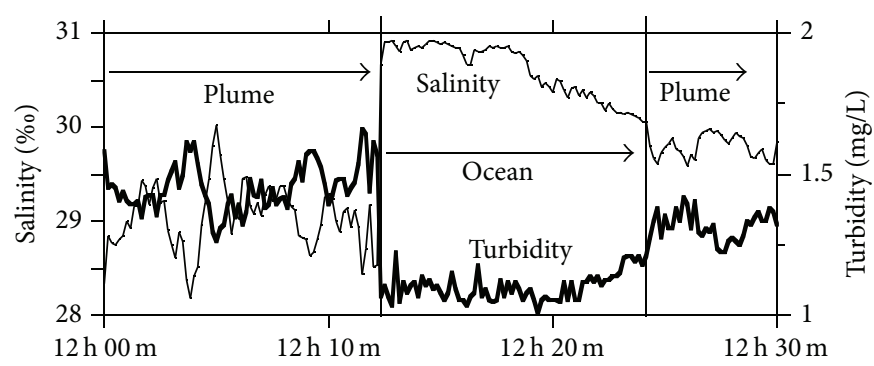

(c)

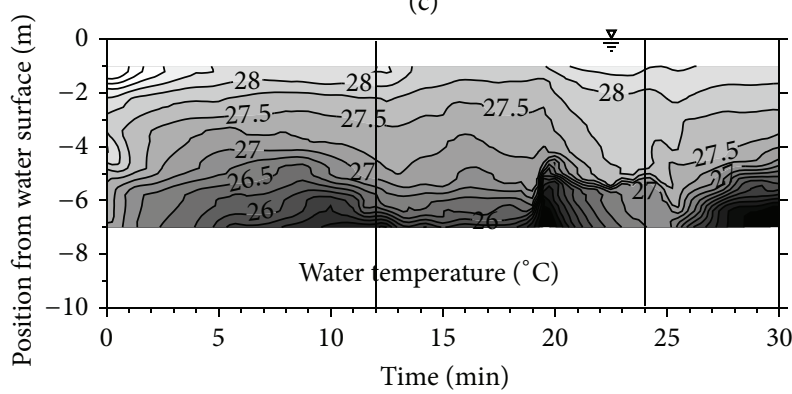

(d)

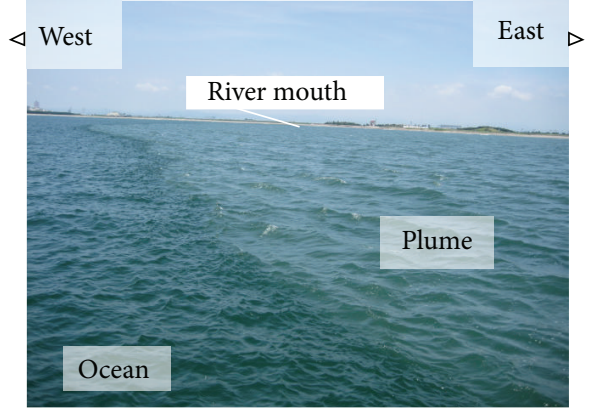

(b) 


\section{Capability of the X-Band Radar to Observe River Plume Fronts}

In the previous sections, we confirmed that the streaky patterns captured in the time-averaged radar images correspond to the river plume fronts. We will discuss here the detection capability of river plume fronts with the X-band radar.

As shown in Figure 2, the definition of the streaky pattern, or the river plume front, varies in the time-averaged radar images. To explore the dependence of visibility on various environmental conditions, a collaborator assessed the definition of the river plume fronts, or the front intensity, into three levels by visual inspection: 0 for absent, 2 for well defined, and 1 for intermediate definition (see the bracketed digits in the captions of Figure 2). The relationship between this subjective assessment and environmental conditions is discussed first from the comparison of the hourly variation of the front intensity and river water level and wind speed and direction and then from a statistical viewpoint in the following.

Figure 5 displays some environmental conditions for one week in December of 2007: the variations of hourly water level record in the river channel and of the river plume front definition with the rate of change of the hourly water level of the river channel, the hourly wind speed and direction displayed as vectors, and a projection of the square of the wind speed along the east-west direction. Some examples of time-averaged radar images captured during this period are already shown in Figure 2. The water surface levels were measured at the Nakanomachi gauging station, $9 \mathrm{~km}$ from the river's mouth, and the Kakezuka gauging station, $4 \mathrm{~km}$ from the mouth in the tidal range (both stations operated by the Ministry of Land, Infrastructure, Transport, and Tourism). Wind speed and direction were measured at the Iwata weather station, $9 \mathrm{~km}$ northeast of the mouth (operated by the Japan Meteorological Agency). See Figure 1(a) for their locations. The area is a fluvial plain, and the ground level of the weather station is $1 \mathrm{~m}$ above the mean sea level. The anemometer is mounted at a height of $10 \mathrm{~m}$ from the ground. The 10-minute means of wind speed and direction are released by the agency every hour with a resolution of one meter per second and in sixteen azimuth directions.

The water level measured at Nakanomachi is constant, showing that there was no fluctuation in the river flow during the period. Since the Kakezuka gauging station is in the tidal range, the drift in the daily mean of the water level might be affected by factors such as the phase of the tidal cycle, wave breaking, and the corresponding wave setup at the river's mouth (Figure 5(a)). Nevertheless, the rate of water level change scatters around zero and is being used as an approximate indicator for the tidal flow rate at the river mouth (Figure 5(b)). The square of the easterly projection of the wind speed is displayed as an indicator of the wind stress component along the coast, which should promote the growth of ripple waves propagating alongshore (Figure 5(d)).

The diagrams indicate that the definition becomes larger mostly when the water level is falling, or the tide is ebbing, and the river water merges with the sea. There is, however, a period with no river plume front apparent in the images

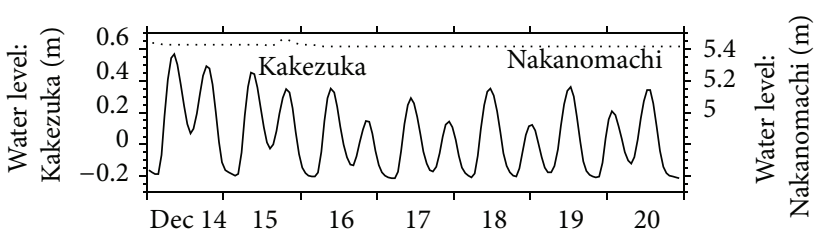

(a)

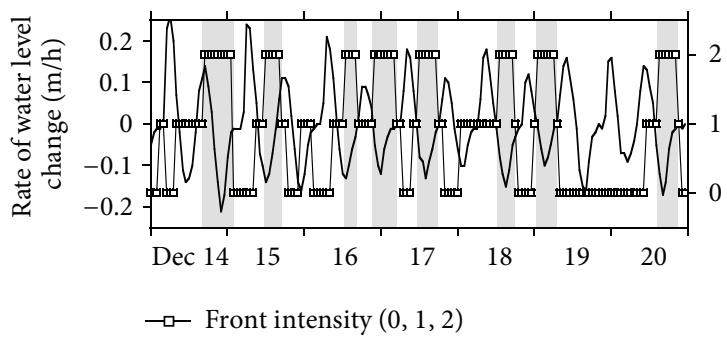

(b)

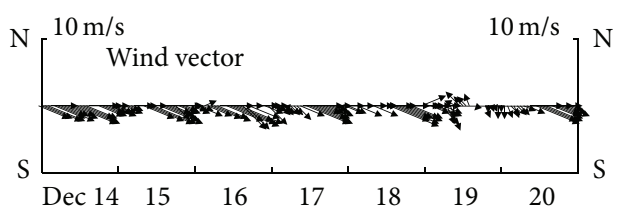

(c)

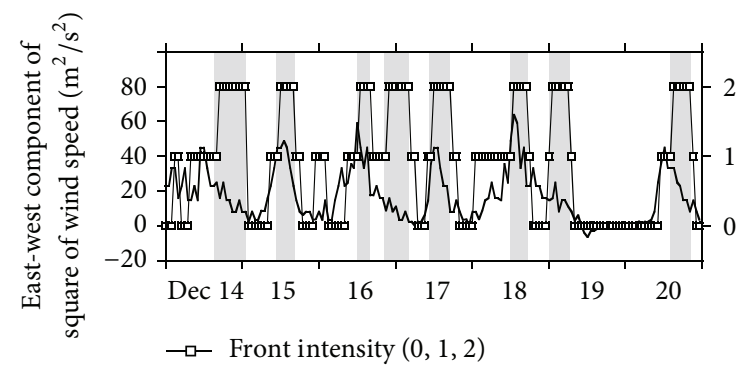

(d)

FIGURE 5: Variations of (a) water levels measured at gauging stations in the river channel: Nakanomachi, $9 \mathrm{~km}$, from the river mouth, and Kakezuka, $4 \mathrm{~km}$, from the river mouth, (b) definition of the river plume front (thin solid line with open square) captured in the timeaveraged radar image (right axis) and rate of water level change at Kakezuka (solid line, left axis), (c) wind vector measured at Iwata weather station, and (d) square of east-west projection of wind speed (solid line, left axis), for the period of 14 to 20 December, 2007. Refer to Figure 1 for the locations of the gauging and weather stations.

even though the water level was decreasing. During these periods, from $8 \mathrm{~h}$ of 19th December, 2007, to the $10 \mathrm{~h}$ of 20th, the wind speed as well as the easterly projection of the square of the wind speed was small compared to other periods, suggesting that wind speed and direction play an important role in detecting the river plume front with the radar.

Macroscopic dependence of the river plume front definitions on the water level variation and wind speed and direction has been assessed with the time-averaged radar images collected for a year, from June, 2007, to May, 2008. Of 7302 images, 880 images were classified into definition level 2, 1810 into level 1, and 4612 into level 0. Figure 6 


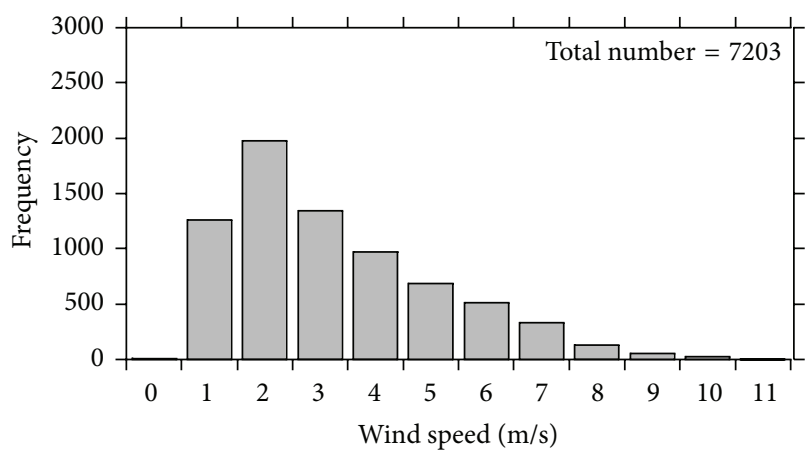

(a)

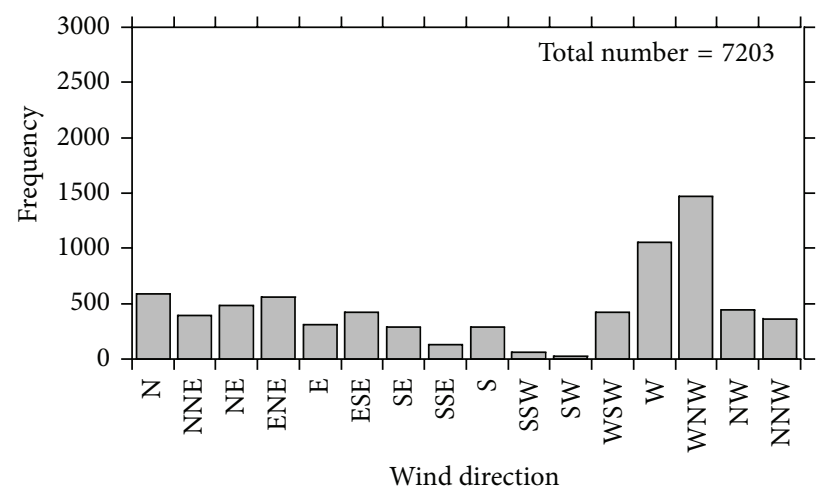

(b)

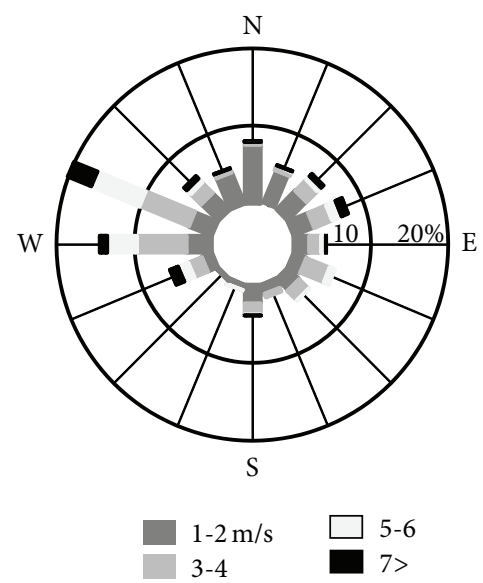

(c)

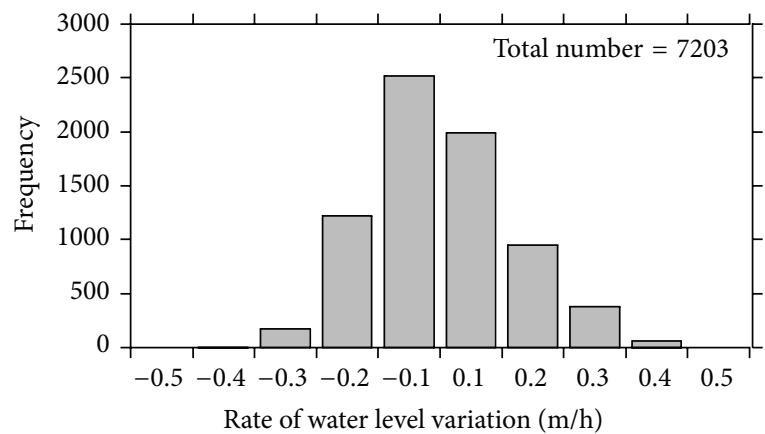

(d)

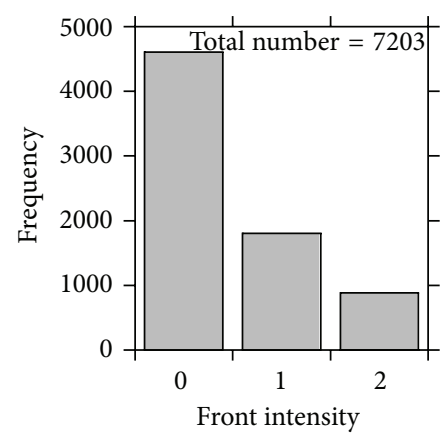

(e)

FIGURE 6: Histograms of (a) wind speed, (b) wind direction, and (c) wind rose measured at the Iwata weather station, histograms of (d) rate of water level variation measured at the Kakezuka gauging station, and (e) front intensity for the period of June, 2007, to May, 2008. Number of analyzed events is 7302 .

contains histograms of wind speed and direction, wind rose measured at the Iwata weather station, and histograms of the rate of water level variation measured at the Kakezuka gauging station and the front intensity for the period of June, 2007 , to May, 2008. The prevailing winds from WNW and W are observed mostly in the winter. The histogram for the rate of water level variation suggests that sea water intrusion into the river channel during tidal flooding periods is larger than the outflow during ebbing periods.

Figure 7 has distributions of the mean front intensity and wind speeds with respect to the rate of water level variation and wind direction. The mean of the front intensity (top row) is estimated from a simple arithmetic average, and its breakdown is given in the bottom row. The middle row displays the wind speed components in the northsouth and east-west directions estimated from the average of the absolute value of the projections of the wind velocity vector. All the panels in the middle row indicate that the strength of the wind remained relatively constant during tidal cycles.

Figure 7(a) shows the results for all wind conditions (number of events $n=7302$ ), whereas Figures $7(b)$ and 7 (c) show the results for east/west winds $(n=4245)$ and north/south winds $(n=1819)$. These results suggest higher definition is frequently observed when the water level is falling and the wind is blowing along the coast. In contrast, the definition decreases when the wind blows perpendicular to the coast, that is, for southerly and northerly winds. Since the number of samples for north/south winds is small compared to those for east/west winds, another result for east/west wind speeds below $2 \mathrm{~m} / \mathrm{s}$ is given in Figure 7(d) $(n=1061)$. This result assures that the smaller definitions for north/south winds are not due to the fewer occurrences and low wind speeds; mean front intensities for east/west winds are higher even for lower wind speeds compared to those for north/south winds, implying the radar can better detect the occurrence of river plume fronts when an east or west wind is prevailing.

Table 1 shows the joint distribution of mean front intensity of the river plume front for different wind directions and wind speeds. Higher definition is frequently observed when the wind is blowing along the coast and the wind speed exceeds $3 \mathrm{~m} / \mathrm{s}$. The definition becomes relatively smaller when the wind blows perpendicular to the coast, that is, for south and north winds. This result again suggests the radar is not capable of detecting the occurrence of river plume fronts 


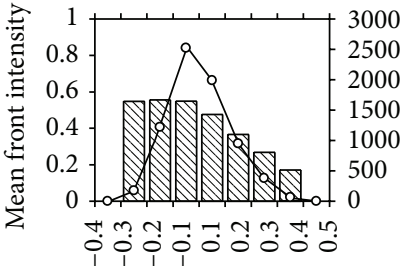

Rate of water level variation $(\mathrm{m} / \mathrm{h})$

- - Frequency

$\mathbb{}$ Mean front intensity

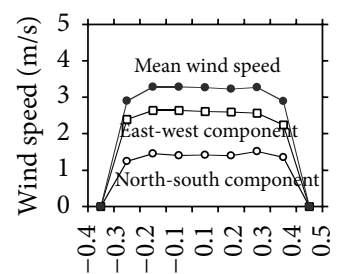

Rate of water level variation $(\mathrm{m} / \mathrm{h})$

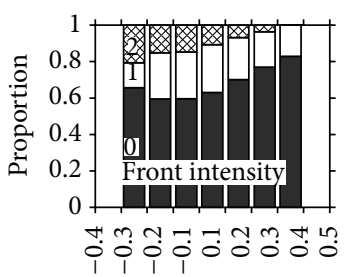

Rate of water level variation $(\mathrm{m} / \mathrm{h})$

(a) Statistics for all wind conditions $(n=7302)$

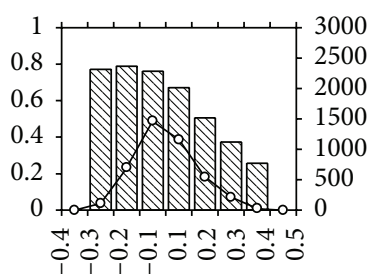

Rate of water level variation $(\mathrm{m} / \mathrm{h})$

-o- Frequency

$\triangle$ Mean front intensity

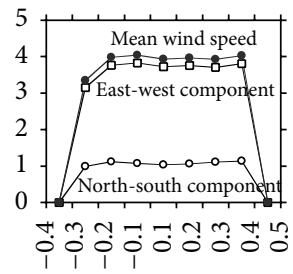

Rate of water level variation $(\mathrm{m} / \mathrm{h})$

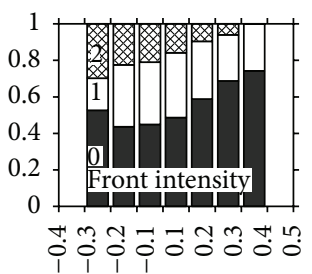

Rate of water level variation $(\mathrm{m} / \mathrm{h})$

(b) Statistics for eastern and western winds $(n=4245)$. ENE, E, ESE, WSW, W, and WNW

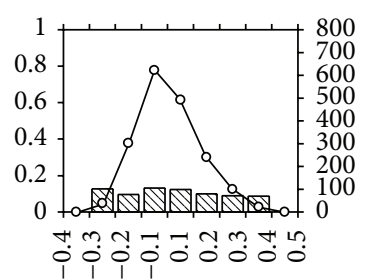

Rate of water level variation $(\mathrm{m} / \mathrm{h})$

-

$\triangle$ Mean front intensity

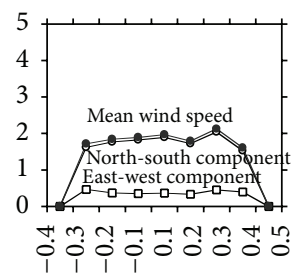

Rate of water level variation $(\mathrm{m} / \mathrm{h})$

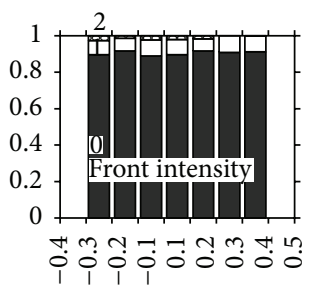

Rate of water level variation $(\mathrm{m} / \mathrm{h})$

(c) Statistics for northern and southern winds $(n=1819)$.

NNW, N, NNE, SSW, S, and SSE

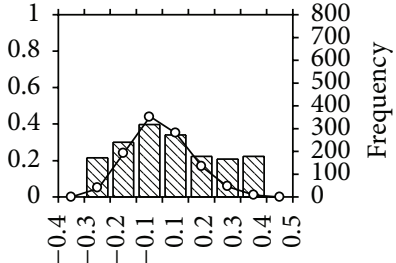

Rate of water level variation $(\mathrm{m} / \mathrm{h})$

-o- Frequency

$\nabla$ Mean front intensity

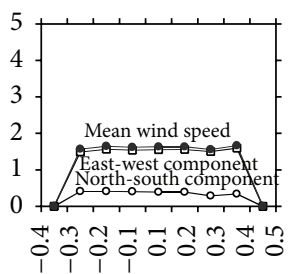

Rate of water level variation $(\mathrm{m} / \mathrm{h})$

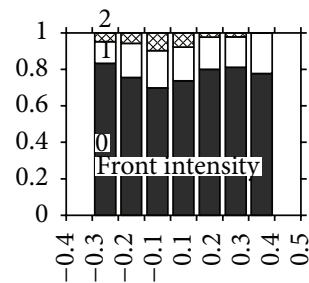

Rate of water level variation $(\mathrm{m} / \mathrm{h})$

(d) Statistics for east-western wind component below $2 \mathrm{~m} / \mathrm{s}(n=1061)$. ENE, E, ESE, WSW, W, and WNW

Figure 7: Mean front intensity and wind speed with respect to the rate of water level variation. Top row: mean front intensity and frequency of events. Middle row: mean wind speed and means of absolute value of east-west and north-south wind components. Bottom row: proportions of front intensities identified (a) for all wind conditions, (b) for east and west winds, (c) for north and south winds, and (d) for east and west winds below $2 \mathrm{~m} / \mathrm{s}$. Class " $0.1 \mathrm{~m} /$ hour" is for the range of $0.0 \mathrm{~m} /$ hour to $0.1 \mathrm{~m} /$ hour and " $-0.1 \mathrm{~m} /$ hour" for $-0.1 \mathrm{~m} /$ hour to $0.0 \mathrm{~m} / \mathrm{hour}$.

in weak wind conditions or when a north or south wind prevails.

\section{Discussion and Concluding Remarks}

The radar detects reflection from the ripple waves by Bragg scattering [14], which becomes stronger when the directions of the radar beam emission and surface water wave propagation match. It is confirmed that the streaky features captured in the time-averaged radar images represent the river plume fronts, the boundary lines between the river and sea water. The imaging by the radar is schematically shown in Figure 8. If river and sea water meet, a strip extending offshore from the vicinity of the river's mouth is formed, along which current convergence and a resulting downwards flow occur. This is confirmed from the results of field measurements of temperature distribution. Previous reports also depict similar flow structures along the front $[3,4]$. Local winds cause growth of ripple waves along the wind direction. As these waves travel across the river plume front, they are amplified and steepened by the convergence flow and cause a higher return signal of the emitted radar beam along the river plume front. This conclusion is supported by the fact that the definition of the river plume front is lesser when the alongshore wind speed is small or when north or south winds prevail. Since the river plume fronts extend mostly in the north-south direction due to the orientation of the river's mouth, any ripple waves generated by north/south winds travel along the front and are consequently amplified at the front only slightly.

Alpers [9] discusses the imaging mechanism of oceanic internal waves with satellite radars, which is similar to the present discussion. If an internal wave exists, horizontal flows are induced along the sea surface, resulting in local amplification of surface waves and higher backscatter of radar beams emitted from space by enhanced Bragg scattering. 
TABLE 1: Mean front intensity of the river plume front with respect to the wind speed and direction. The frequency is the number of images in the category. The three numbers shown in the breakdown denote the percentage of images assessed with front intensities of 0,1 , and 2 , respectively.

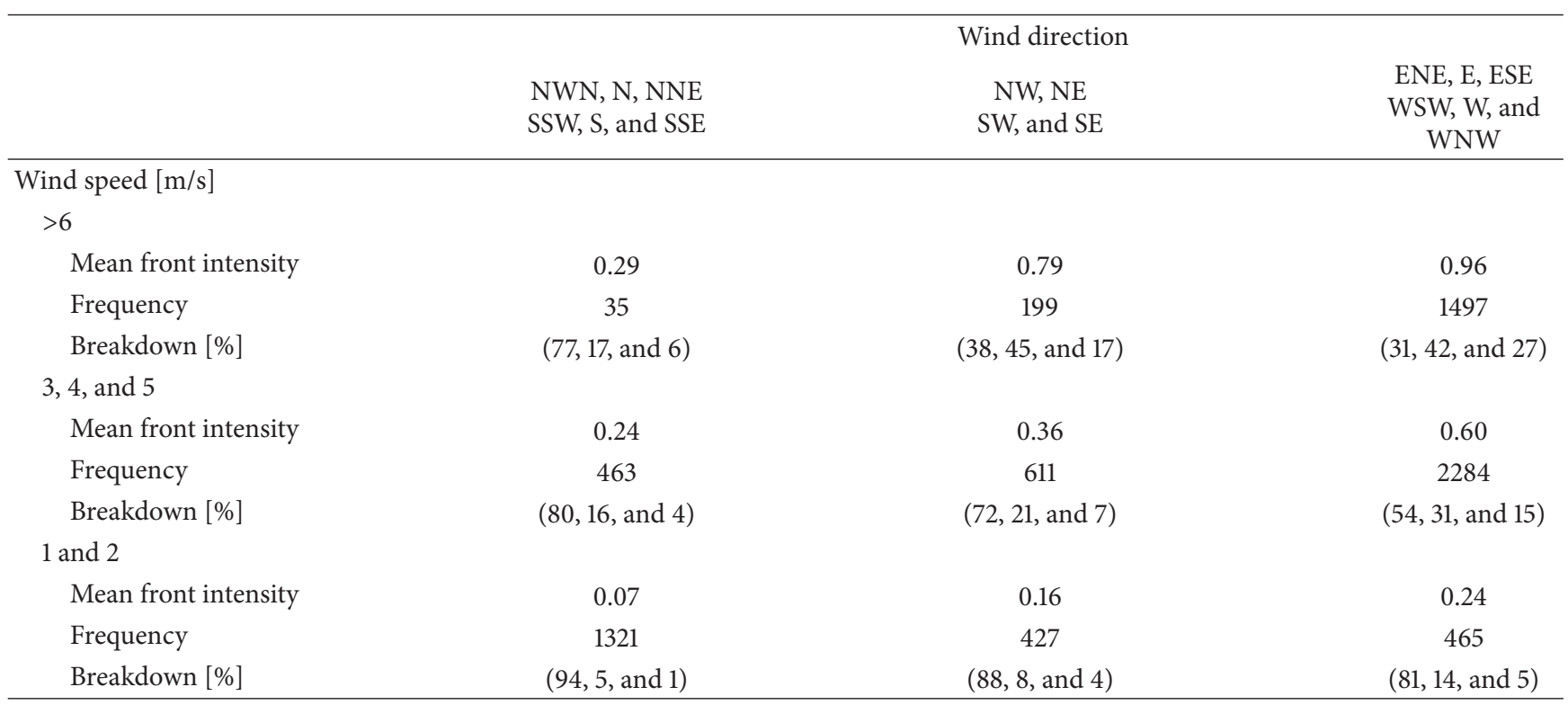

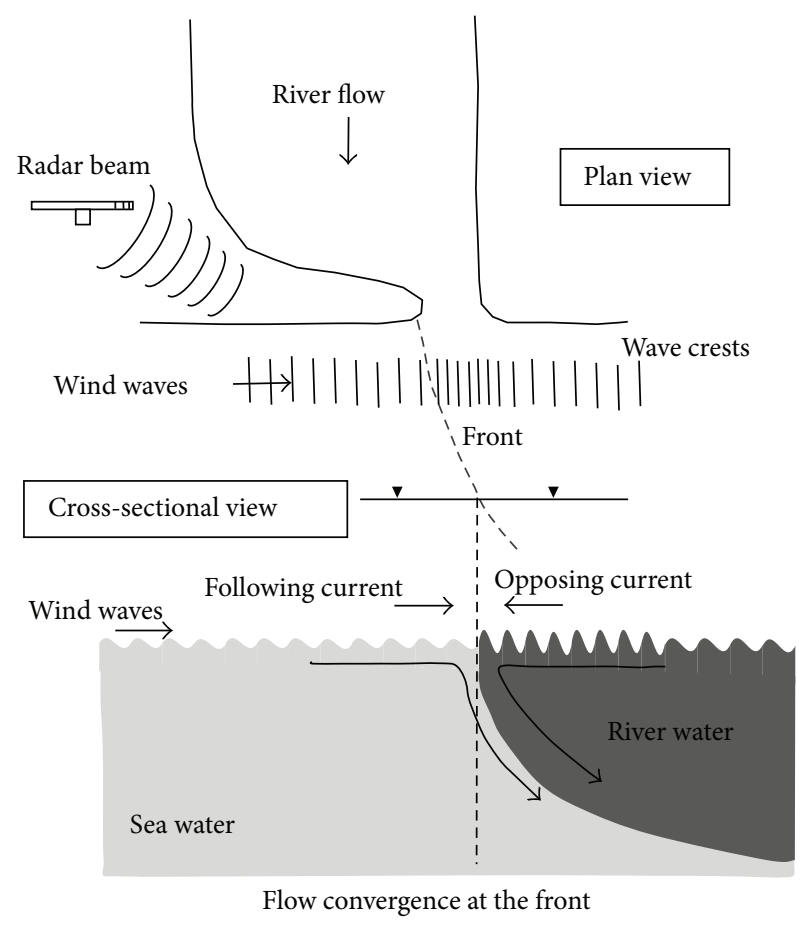

FIGURE 8: Schematic of imaging mechanism of the river plume front by the X-band radar. Flow convergence at the front amplifies local wind waves that propagate across the plume and on the opposing current, yielding higher backscatter of the emitted radar beam.

In addition, the present study demonstrates that the amplification mechanism is dependent on the wind direction and confirms the visibility of the features in the radar images, which has not been discussed before.
Marmorino et al. [15] report observations of oceanic fronts approaching the shore with land-based X-band radar at Duck, North Carolina, USA. The observational setup is similar to the present; a horizontally polarized radar is employed at a grazing angle. They do not explain the details of the imaging mechanism; however, convergence flow at the surface should have amplified the surface waves yielding higher backscatter.

In summary, we have the following:

(1) Time-averaged X-band radar images of the mouth of the Tenryu River capture river plume fronts extending offshore from the river's mouth as bright streaks.

(2) Comparisons between satellite optical images and time-averaged radar images confirm that streaky features in the time-averaged radar images represent color fronts, or river plume fronts. Further corroboration comes from field observations of water temperature, salinity, and turbidity conducted simultaneously with the radar measurement across the river plume front. When the survey ship crossed the river plume front (confirmed by visual inspection from the ship), the measured properties varied discontinuously, suggesting that water from the river and sea met there and also that a downwards current was present.

(3) The definition of the river plume front varies in the time-averaged radar images. The definition was visually assessed and compared with the rate of water level variation and with the wind speed and direction. The radar captures well river plume fronts when the river water level is decreasing and the wind speed exceeds $3 \mathrm{~m} / \mathrm{s}$ alongshore. The wind generates ripple waves, causing higher backscatter of the emitted radar beam 
when they travel across the plume. The observations are expanded upon to illustrate a detailed imaging mechanism of the river plume front with X-band radars.

\section{Highlights}

(i) A land-based X-band radar was employed to observe river plume fronts.

(ii) Features captured in the radar images were checked against satellite and field data.

(iii) The fidelity of radar observation of fronts was assessed and found to be correlated to wind direction.

\section{Conflict of Interests}

The author declares that there is no conflict of interests regarding the publication of this paper.

\section{Acknowledgments}

The author is grateful for the support by Mr. Takahashi Yu and Takahashi Ryo, former graduate students, and Professors Sato Shinji and Tajima Yoshimitsu of the University of Tokyo in the field observations. Mr. Takahashi Yu's laborious assistance in the determination of the front intensity is especially highly appreciated. This research is supported by the Special Coordination Funds for Promoting Science and Technology of the Ministry of Education, Culture, Sports, Science, and Technology, and the River Fund, The Foundation of River \& Watershed Environment Management. Finally, the author is thankful to the anonymous reviewers who carefully checked the initial draft and gave informative suggestions to improve the work.

\section{References}

[1] L. F. Kilcher and J. D. Nash, "Structure and dynamics of the Columbia River tidal plume front," Journal of Geophysical Research: Oceans, vol. 115, no. 5, Article ID C05S90, 2010.

[2] R. W. Garvine and J. D. Monk, "Frontal structure of a river plume," Journal of Geophysical Research, vol. 79, pp. 2251-2259, 1974.

[3] D. A. Luketina and J. Imberger, "Characteristics of a surface buoyant jet," Journal of Geophysical Research, vol. 92, pp. 54355447, 1987.

[4] G. O. Marmorino and C. L. Trump, "Gravity current structure of the Chesapeake Bay outflow plume," Journal of Geophysical Research: Oceans, vol. 105, no. 12, pp. 28847-28861, 2000.

[5] M. Pritchard and D. A. Huntley, "A simplified energy and mixing budget for a small river plume discharge," Journal of Geophysical Research: Oceans, vol. 111, no. 3, Article ID C03019, 2006.

[6] U. Wolff, J. Seemann, C. M. Senet, and F. Ziemer, "Analysis of morphodynamical processes with a nautical X-band radar," in Mustererkennung 1999-21. DAGM-Symposium Bonn, 1517 September 1999, Informatik aktuell, pp. 372-380, Springer, Berlin, Germany, 1999.
[7] K. Hessner, A. Rubino, P. Brandt, and W. Alpers, “The Rhine outflow plume studied by the analysis of synthetic aperture radar data and numerical simulations," Journal of Physical Oceanography, vol. 31, no. 10, pp. 3030-3044, 2001.

[8] D. A. Jay, J. Pan, P. M. Orton, and A. R. Horner-Devine, "Asymmetry of Columbia River tidal plume fronts," Journal of Marine Systems, vol. 78, no. 3, pp. 442-459, 2009.

[9] W. Alpers, "Theory of radar imaging of internal waves," Nature, vol. 314 , no. 6008 , pp. 245-247, 1985.

[10] W. Alpers, G. Campbell, H. Wensink, and Q. Zheng, "Underwater topography," in Synthetic Aperture Radar Marine User's Manual, chapter 10, US Department of Commerce, National Oceanic and Atmospheric Administration, 2004.

[11] R. Romeiser and W. Alpers, "An improved composite surface model for the radar backscattering cross section of the ocean surface. 2. Model response to surface roughness variations and the radar imaging of underwater bottom topography," Journal of Geophysical Research, vol. 102, no. 11, pp. 25251-25267, 1997.

[12] S. Takewaka, Y. Takahashi, Y. Tajima, and S. Sato, "Observation of morphology and flow motion at the river mouth of Tenryu with X-band radar," in Proceedings of the Coastal Dynamics, Impacts of Human Activities on Dynamic Coastal Processes, Tokyo, Japan, September 2009.

[13] S. Takewaka, "Measurements of shoreline positions and intertidal foreshore slopes with X-band marine radar system," Coastal Engineering Journal, vol. 47, no. 2-3, pp. 91-107, 2005.

[14] M. I. Skolnik, Radar Handbook, McGraw-Hill, 2nd edition, 1990.

[15] G. O. Marmorino, A. L. Cooper, R. P. Mied, G. J. Lindemann, D. B. Trizna, and D. L. Porter, "Onshore propagation of a buoyant ocean front observed using a shore-based marine radar," Continental Shelf Research, vol. 24, no. 9, pp. 951-964, 2004. 


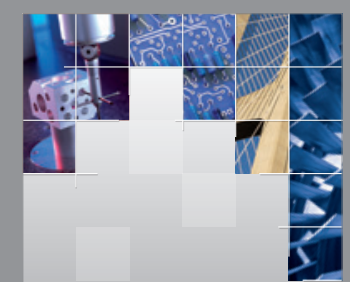

\section{Enfincering}
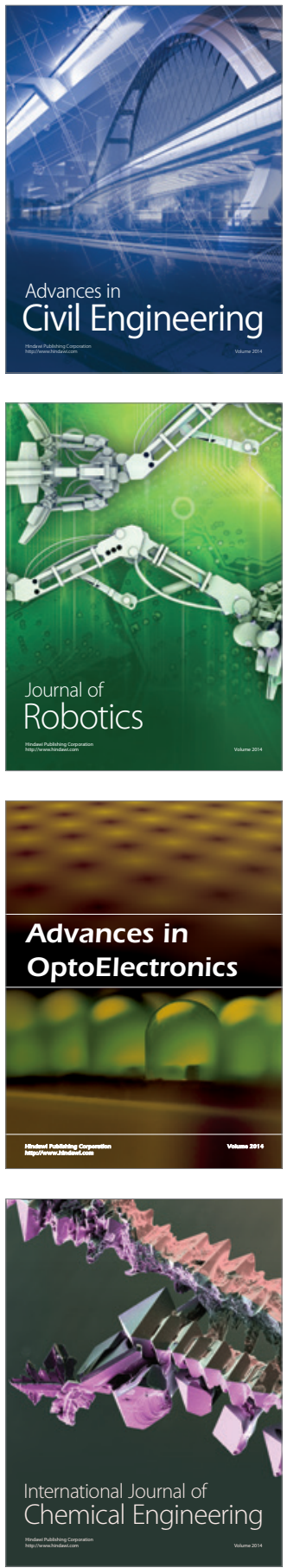

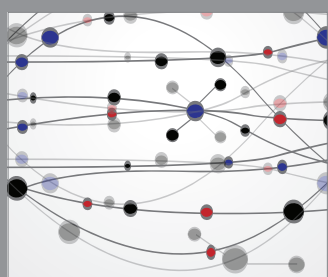

The Scientific World Journal

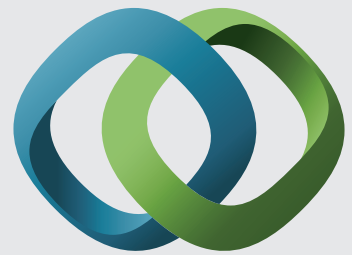

\section{Hindawi}

Submit your manuscripts at

http://www.hindawi.com
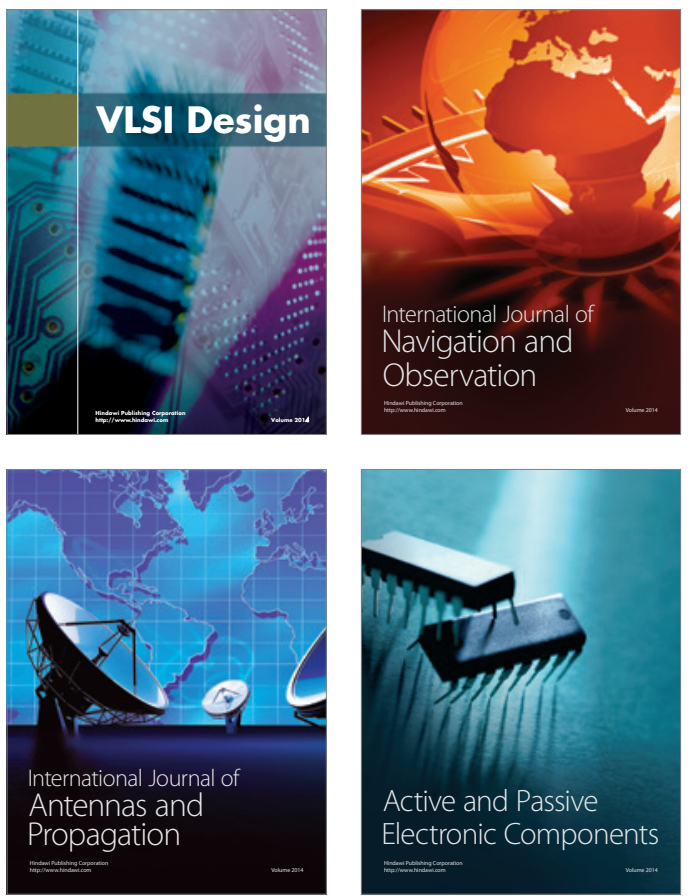
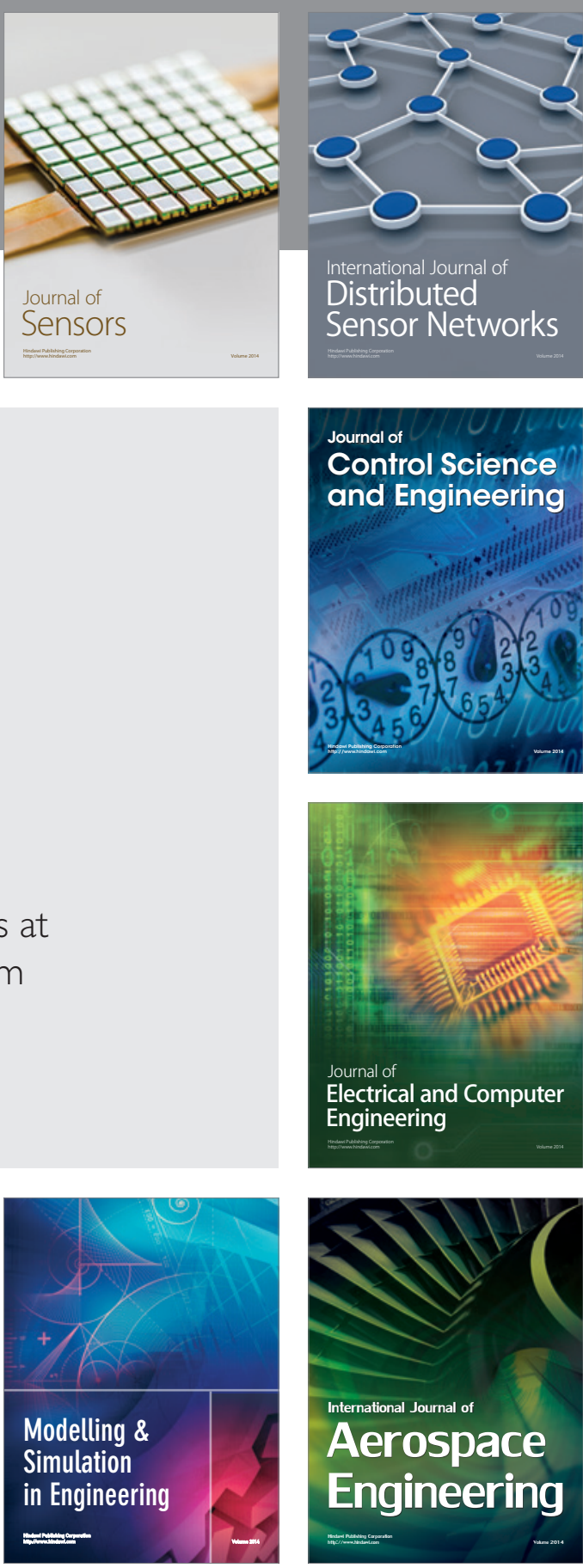

International Journal of

Distributed

Sensor Networks

Journal of

Control Science

and Engineering
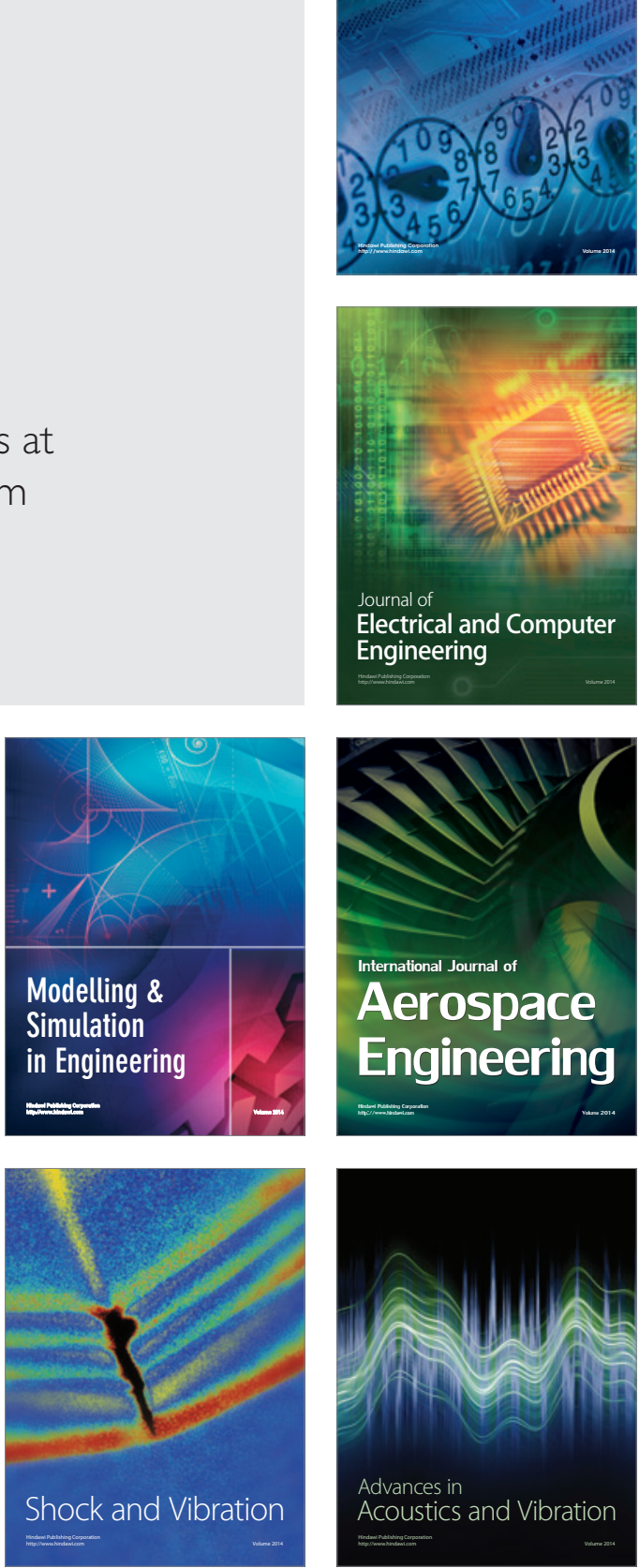